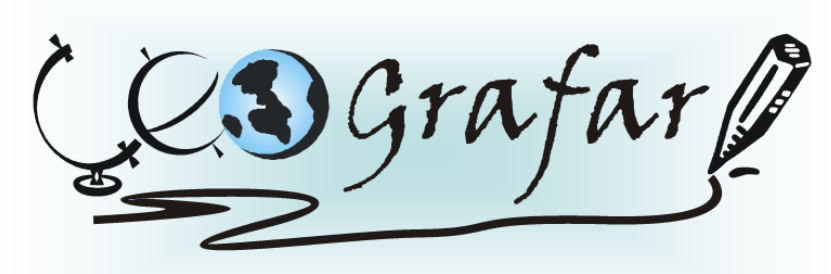

Revista Eletrônica do Programa de Pós-Graduação em Geografia - UFPR

\title{
CLIMA E DISTRIBUIÇÃO DOS SOLOS ZONAIS NO RIO GRANDE DO SUL - BRASIL
}

\author{
CLIMATE AND ZONAL SOIL DISTRIBUTION IN RIO GRANDE DO SUL - BRAZIL \\ (Recebido em 06-01-2016; Aceito em 20-02-2017)
}

\author{
Elsbeth Léia Spode Becker \\ Professora Adjunta na Área das Ciências Humanas no Centro Universitário Franciscano - \\ UNIFRA. \\ elsbeth.geo@gmail.com
}

\begin{abstract}
Galileo Adeli Buriol Professor Titular na Área das Ciências Sociais Aplicadas no Centro Universitário Franciscano UNIFRA. galileo@unifra.br

Nereu Augusto Streck Professor Titular no Curso de Agronomia na Universidade Federal de Santa Maria - UFSM. nastreck@gmail.com
\end{abstract}

\section{Resumo}

O clima tem grande influência na formação dos solos, além da ação integrada de fatores como material de origem, relevo, organismos e tempo. Os solos zonais são formados quando o clima é o fator preponderante no intemperismo. Neste estudo objetivou-se evidenciar os solos zonais do Rio Grande do Sul e determinar sua localização. A espacialização das disponibilidades climáticas para 0 desenvolvimento de solos zonais foi realizada utilizando-se as médias anuais, as médias dos totais anuais de precipitação pluvial e as médias anuais de temperatura do ar, entre 1931 e 1960, de 41 estações meteorológicas do $8^{\circ}$ Distrito de Meteorologia ( $8^{\circ} \mathrm{DISME}$ ). Constatou-se que os solos zonais do Rio Grande do Sul compreendem solos Lateríticos e solos Pedalférricos. Solos de clima muito úmido situam-se na metade norte do Estado com médias anuais de precipitação pluvial acima de $1.500 \mathrm{~mm}$ e são representados pelos solos Lateríticos, predominantemente, os Latossolos. Os Pedalférricos ocorrem, preferencialmente, em regiões de clima temperado e são descritos como solos com pronunciada lixiviação, que ocorrem em condições de intemperismo químico com índices de precipitação anual acima de $600 \mathrm{~mm}$. No Rio Grande do Sul as condições climáticas ideais para a formação desses solos são registradas nas estações meteorológicas localizadas na Depressão Central (com exceção das estações de Santa Maria e Santa Cruz do Sul), no Escudo Sul-rio-grandense (com exceção de Caçapava do Sul), na Planície Costeira e no Planalto Norte-rio-grandense (apenas a região de Vacaria). São representados, predominantemente pelos Neossolos e Cambissolos.

Palavras-Chave: Lateríticos; Pedalférricos; Latossolos. 


\begin{abstract}
The weather has great influence on the soils formation, besides the integrated action of factors as source material, relief, organisms and time. The zonal soils are formed when the weather is a major factor in weathering. This study aimed to highlight the zonal soils of Rio Grande do Sul and determine its location. The spatial distribution of climate resources for the development of zonal soils was performed using the annual averages, the annual average of total pluvial precipitation and the annual average of air temperature, between 1931 and 1960 of 41 weather stations of the 8th Meteorology District (8 DISME). It was found that the zonal soils of Rio Grande do Sul comprehend Lateritic soils and Pedalférricos soils. Soils of very humid climate are located in the northern half of the state with annual average of total pluvial precipitation above $1,500 \mathrm{~mm}$ and are represented by Lateritic soils predominantly Oxisols. The Pedalférricos occur preferentially in temperate regions and are described as soils with pronounced leaching occurring in chemical weathering conditions with annual average of total pluvial precipitation above $600 \mathrm{~mm}$. In Rio Grande do Sul the ideal climatic conditions for the formation of these soils are recorded at meteorological stations located in Central Depression (with the exception of stations of Santa Maria and Santa Cruz do Sul), in South-Riograndense Shield (with the exception of Cacapava do Sul), in the coastal plain and in the North of Rio Grande Plateau just Vacaria region and are represented predominantly by Neossolos and Cambisols.
\end{abstract}

Keywords: Laterites; Pedalfers; Latossols.

\title{
Introdução
}

A formação do solo decorre do intemperismo das rochas na superfície terrestre, provocado pela ação integrada de fatores como clima, material de origem, relevo, organismos e tempo (JENNY, 1941). Solos zonais são formados quando o clima é o fator preponderante no intemperismo. No Rio Grande do Sul existem poucos estudos que relacionam as condições climáticas de temperatura do ar e de precipitação pluvial com a formação de solos zonais.

A espessura do perfil de solo depende do clima, do tempo de formação do solo e da composição da rocha-matriz (PRESS et al., 2006). O perfil é estruturado verticalmente, a partir da rocha matriz, na base, sobre a qual forma-se o saprólito e o solum, que constituem juntos, o manto de alteração ou regolito (AZEVEDO; DALMOLIN, 2006). Os materiais do perfil vão se tornando tanto mais diferenciados com relação à rocha matriz em termos de composição, textura e estrutura, quanto mais afastados se encontram dela. Sendo dependente, especialmente, do clima, o intemperismo e a pedogênese ocorrem de maneira distinta nas diferentes zonas climáticas do globo, levando à formação de perfis de alteração compostos de horizontes de diferente espessura e composição. A energia de desintegração e decomposição das rochas, segundo Zakarovi citado por VIEIRA (1975), aumenta gradualmente das regiões frias para as quentes.

Nos climas mais frios, a alteração afeta, normalmente, apenas os minerais primários menos resistentes. Os minerais primários mais resistentes permanecem inalterados durante um tempo geológico muito maior. Tanto o intemperismo intenso como um longo período de exposição à 
meteorização diminuem a influência da rocha-matriz. Solos muito antigos e de regiões úmidas tendem a ser homogêneos e apresentam perfis bem desenvolvidos.

Climas quentes e úmidos promovem rapidamente a alteração dos minerais da rocha matriz, pois a percolação constante da água permite a evolução permanente da decomposição dos minerais. Enquanto que numa região de clima seco, os minerais permanecem praticamente insolúveis ou, quando ocorre a decomposição, esta é muito lenta. Os climas quentes também têm influência na vegetação e sobre a matéria orgânica produzida a partir da decomposição. Os ácidos orgânicos reagem com os elementos da rocha matriz no clima temperado úmido, enquanto que a matéria orgânica é rapidamente destruída por oxidação em climas quentes úmidos (SUGUIO, 2003). O clima, portanto, é um dos fatores de maior intensidade no condicionamento no intemperismo em função, principalmente, da precipitação pluvial e da temperatura.

Bigarella (1994) considera que pode-se estabelecer uma correlação entre os tipos e intensidade de intemperismo e as diferentes regiões climáticas da Terra. Para este autor, a máxima lixiviação processa-se nas áreas tropicais (aproximadamente 10 graus de latitudes norte e sul), caracterizadas por grande volume de precipitação pluvial e altas temperaturas, sendo ocupadas, especialmente, pelas florestas pluviais. Nas faixas de latitudes periféricas às florestas pluviais, ocorrem regiões tropicais caracterizadas pela sazonalidade da precipitação pluvial. A fase úmida sazonal favorece o intemperismo químico profundo, mas o período seco favorece a oxidação do alumínio e do ferro. Nas latitudes médias ocorre a podsolização nas zonas de climas úmidos e com vegetação natural de bosques. Nas zonas de tundras e zonas desérticas e semidesérticas, o intemperismo químico é desprezível pela baixa temperatura e escassez de água, respectivamente, estabelecendo-se faixas latitudinais de intemperismo químico e biológico mínimos.

Press et al. (2006) distinguem três grupos principais de solos em função do clima: Pedalférricos, Lateríticos e Pedocalcários. Strahler \& Strahler (2005) descrevem solos Pedalférricos como solos de climas úmidos, com pronunciada lixiviação e mantidos os valores médios anuais de precipitação pluvial acima de $600 \mathrm{~mm}$.

O clima tem grande influência, também, na formação dos solos Lateríticos. Normalmente são necessárias condições de alta precipitação pluvial e temperatura para que a alteração da rocha adquira condições para a laterização (TEIXEIRA et al., 2003). O intemperismo é intenso em climas quentes e úmidos, os solos profundos e a vegetação de grande porte. Estes condicionantes aceleram a lixiviação dos minerais solúveis e facilmente alteráveis, como a sílica e o carbonato de cálcio, da camada superior do solo desencadeando a laterização e a formação do laterito. 
Os solos Pedocalcários são formados, especialmente, em regiões com escassez de água por longos períodos de tempo, qualidade de climas semiáridos e áridos. Apresentam perfis pouco evoluídos em que predominam as características herdadas do material parental.

Um primeiro nível de divisão de grupos de solos determinados por suas características climáticas foi estabelecido por Marbut (1935). As condições climáticas de latitudes médias condicionam solos dos grupos Pedalférricos e Pedocalcários, excetuando-se, apenas, o sudeste dos Estados Unidos, o sul do Brasil e uma pequena parte do nordeste da Argentina. Apesar da localização geográfica do Rio Grande do Sul, estar em latitudes médias, as condições climáticas, de precipitação pluvial bem distribuída durante 0 ano, indicam possibilidade de formação de solos dos grupos Pedalférricos e Lateríticos.

Streck et al., (2002; 2008) descreveram as diferentes classes de solos do Rio Grande do Sul. Foram uma variedade de tipos distribuídos de forma heterogênea na paisagem. Comentaram que a razão dessa variedade de solos é dada pelo entendimento dos fatores que afetam a sua formação e reforçaram a idéia de que a gênese natural do solo é um processo muito lento. Ainda segundo Streck et al. (2002; 2008), entre os fatores ambientais que mais influenciam na diferenciação dos solos identificados no Rio Grande do Sul destacam-se o material de origem, o relevo e o clima. Destes fatores, o conhecimento das condições climáticas vigentes no Rio Grande do Sul contribui para evidenciar o zoneamento dos grupos de solos e para um melhor entendimento da ocorrência dos diferentes tipos de solos.

Neste estudo objetivou-se evidenciar os solos zonais do Rio Grande do Sul e determinar sua localização.

\section{Material e métodos}

A espacialização das disponibilidades climáticas para o desenvolvimento de solos Lateríticos e Pedalférricos no Estado do Rio Grande do Sul foi realizada utilizando-se as médias anuais as médias dos totais anuais de precipitação pluvial e das médias anuais de temperatura do ar, entre 1931 e 1960, de 41 estações meteorológicas do $8^{\circ}$ DISME (quadro 1). Foram representadas com base nos valores do quadro 1, no programa Spring versão 4.2 e adaptados nos mapas por meio do programa Corel Draw 13. Considerou-se zona preferencial para a formação de solos do grupo Pedalférricos a área geográfica com valores médios anuais de precipitação pluvial acima de 600mm (STRAHLER; STRAHLER, 2005) e para os solos do grupo Lateríticos a área geográfica com precipitação pluvial acima de $1.500 \mathrm{~mm}$ anuais (PRESS et al., 2006).

$\mathrm{Na}$ caracterização de diferentes tipos de solos ocorrentes nas áreas geográficas dos grupos de solos Pedalférricos e Lateríticos foram consideradas as condições climáticas de temperatura e precipitação pluvial e a base geológica segundo o Departamento Nacional da Produção Mineral-DNPM 
(1984b). Foram calculadas as médias mensais de evapotranspiração potencial para os valores de 4 estações meteorológicas pertencentes ao $8^{\circ}$ DISME, período 1931 a 1960, localizadas em diferentes regiões geomorfológicas do Estado do Rio Grande do Sul: Irai e Santo Ângelo (Planalto Norte-riograndense), Encruzilhada do Sul e Piratini (Escudo Sul-rio-grandense), de forma a contemplar as diferentes situações climáticas, geológicas e geomorfológicas do Estado.

Quadro 1: Médias dos totais anuais da temperatura do ar $(T)$ e médias dos totais anuais de precipitação pluvial $(\mathrm{P})$ das estações meteorológicas do Estado do Rio Grande do Sul, pertencentes ao $8^{\circ}$ DISME, utilizadas no estudo, período 1931-1960.

\begin{tabular}{|c|c|c|c|}
\hline ESTAÇÕES METEOROLÓGICAS & ALTITUDE $(m)$ & $\mathrm{T}\left({ }^{\circ} \mathrm{C}\right)$ & $\mathrm{P}(\mathrm{mm})$ \\
\hline Alegrete & 116 & 18.6 & 1574 \\
\hline Bagé & 216 & 17.9 & 1264 \\
\hline Bento Gonçalves & 619 & 16.8 & 1599 \\
\hline Bom Jesus & 1047 & 14.4 & 1545 \\
\hline Caçapava do Sul & 450 & 16.8 & 1588 \\
\hline Cachoeira do Sul & 68 & 18.8 & 1438 \\
\hline Caxias do Sul & 740 & 15.9 & 1663 \\
\hline Cruz Alta & 473 & 18.4 & 1729 \\
\hline Dom Pedrito & 140 & 18.2 & 1359 \\
\hline Encruzilhada do Sul & 420 & 16.5 & 1504 \\
\hline Guaporé & 450 & 16.9 & 1686 \\
\hline Iraí & 227 & 18.8 & 1787 \\
\hline Itaqui & 53 & 20.0 & 1453 \\
\hline Jaguarão & 11 & 17.2 & 1337 \\
\hline Julio de Castilhos & 516 & 18.0 & 1575 \\
\hline Lagoa Vermelha & 805 & 16.7 & 1735 \\
\hline Marcelino Ramos & 383 & 18.8 & 1652 \\
\hline Palmeira das Missões & 634 & 18.1 & 1919 \\
\hline Passo Fundo & 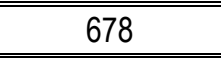 & 17.5 & 1664 \\
\hline Pelotas & 7 & 17.5 & 1405 \\
\hline Piratini & 345 & 16.2 & 1426 \\
\hline Porto Alegre & 10 & 19.5 & 1309 \\
\hline Rio Grande & 8 & 18.1 & 1162 \\
\hline Santa Cruz do Sul & 56 & 19.3 & 1547 \\
\hline Santa Maria & 138 & 19.2 & 1708 \\
\hline Santana do Livramento & 210 & 17.8 & 1388 \\
\hline Santa Rosa & 360 & 19.6 & 1663 \\
\hline Santa Vitória do Palmar & 6 & 16.6 & 1235 \\
\hline Santiago & 426 & 17.9 & 1534 \\
\hline Santo Ângelo & 289 & 19.6 & 1713 \\
\hline São Borja & 96 & 20.1 & 1523 \\
\hline São Francisco de Paula & 912 & 14.4 & 2162 \\
\hline
\end{tabular}


(conclusão)

\begin{tabular}{||l||c|c|c|}
\hline São Gabriel & 124 & 18.5 & 1355 \\
\hline Soledade & 720 & 16.9 & 1986 \\
\hline São Luiz Gonzaga & 254 & 19.7 & 1662 \\
\hline Tapes & 5 & 18.8 & 1213 \\
\hline Taquara & 29 & 19.4 & 1459 \\
\hline Taquari & 76 & 19.1 & 1424 \\
\hline Torres & 43 & 18.3 & 1409 \\
\hline Uruguaiana & 69 & 19.7 & 1346 \\
\hline Vacaria & 955 & 15.2 & 1412 \\
\hline
\end{tabular}

Fonte: Instituto de Pesquisas Agronômicas (1989).

A evapotranspiração potencial foi calculada pelo modelo de Thornthwaite (1931) e apresentada no diagrama de Camargo (1960). Os dados de temperatura média mensal utilizada no cálculo da evapotranspiração potencial foram obtidas do Instituto de Pesquisas Agronômicas (1989), período 19411970, relacionadas no quadro 2.

Quadro 2 - Evapotranspiração potencial $(\mathrm{mm})$ das estações meteorológicas de Iraí, Santo Ângelo, Encruzilhada do Sul e Piratiní, do Estado do Rio Grande do Sul, pertencentes ao $8^{\circ}$ DISME utilizadas no estudo, período 1941-1970 (pelo diagrama de CAMARGO, 1960).

\begin{tabular}{|l||c||c||c||c||c||c||c||c||c||c||c||c||c|}
\hline \multicolumn{1}{|c|}{ E. M. } & jan & fev & mar & abr & mai & jun & jul & ago & set & out & nov & dez & ano \\
\hline \hline Iraí & 131 & 110 & 98 & 68 & 48 & 37 & 36 & 46 & 59 & 80 & 101 & 129 & 943 \\
\hline S. Ang. & 136 & 113 & 101 & 68 & 46 & 32 & 33 & 44 & 54 & 77 & 98 & 130 & 932 \\
\hline En. Sul & 115 & 99 & 89 & 65 & 44 & 33 & 30 & 37 & 48 & 64 & 86 & 109 & 819 \\
\hline Piratiní & 116 & 99 & 89 & 62 & 44 & 28 & 28 & 35 & 45 & 60 & 79 & 110 & 795 \\
\hline
\end{tabular}

Fonte: Instituto de Pesquisas Agronômicas (1989).

No diagrama de Camargo (1960) utilizou-se a evapotranspiração potencial ETp mm/mês pela fórmula ETp = $16(10 T n / I) a$, sendo Tn a temperatura média do mês, I o índice que expressa o nível de calor disponível na região e $\mathrm{n}$ representa o mês do ano.

Os perfis de solos do Rio Grande do Sul utilizados estão descritos em Streck et al. (2002; 2008) e em Azevedo e Dalmolin (2006) e foram selecionados considerando as diferenças entre perfis de solos originados da mesma rocha, basalto (figura 1) ou granito (figura 2) com base no mapeamento do Departamento Nacional da Produção Mineral-DNPM (1984b). Considerou-se, ainda, a distribuição geográfica do intemperismo segundo as condições climáticas de temperatura e de precipitação pluvial e os grupos de solos para as latitudes médias estabelecidas por Marbut (1935) e descritos em Strahler e Strahler (2005). 
Figura 1: Mapa de solos do Estado do Rio Grande do Sul e perfil de Neossolo, Chernossolo e Latossolo com substrato de basalto e respectiva paisagem
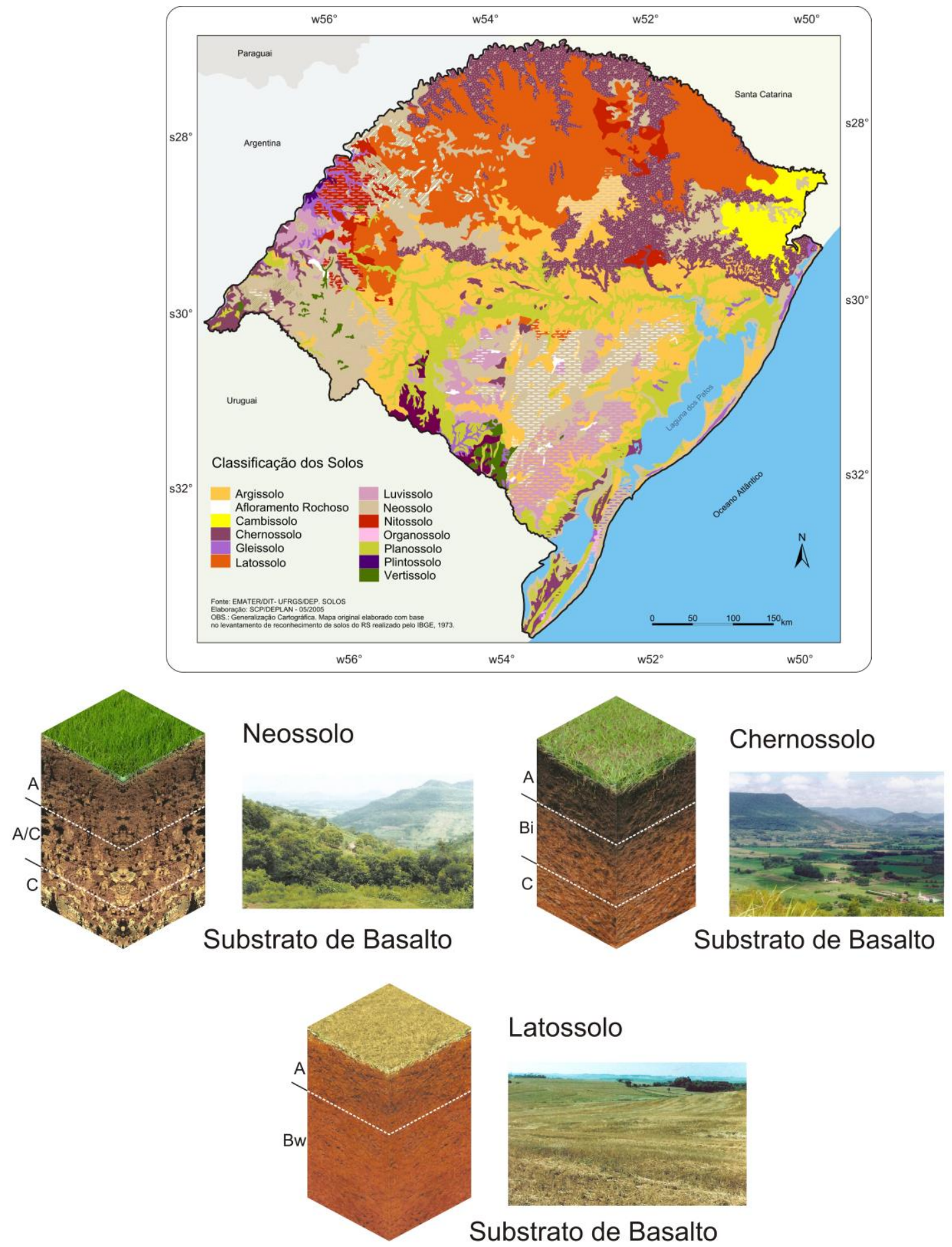

Fonte: Adaptado de EMATER/DIT - UFRGS/DEP. SOLOS e de Streck et al. (2008). 
Figura 2: Mapa de solos do Estado do Rio Grande do Sul e perfil de Neossolo, Cambissolo e Argissolo com substrato de granito e respectiva paisagem

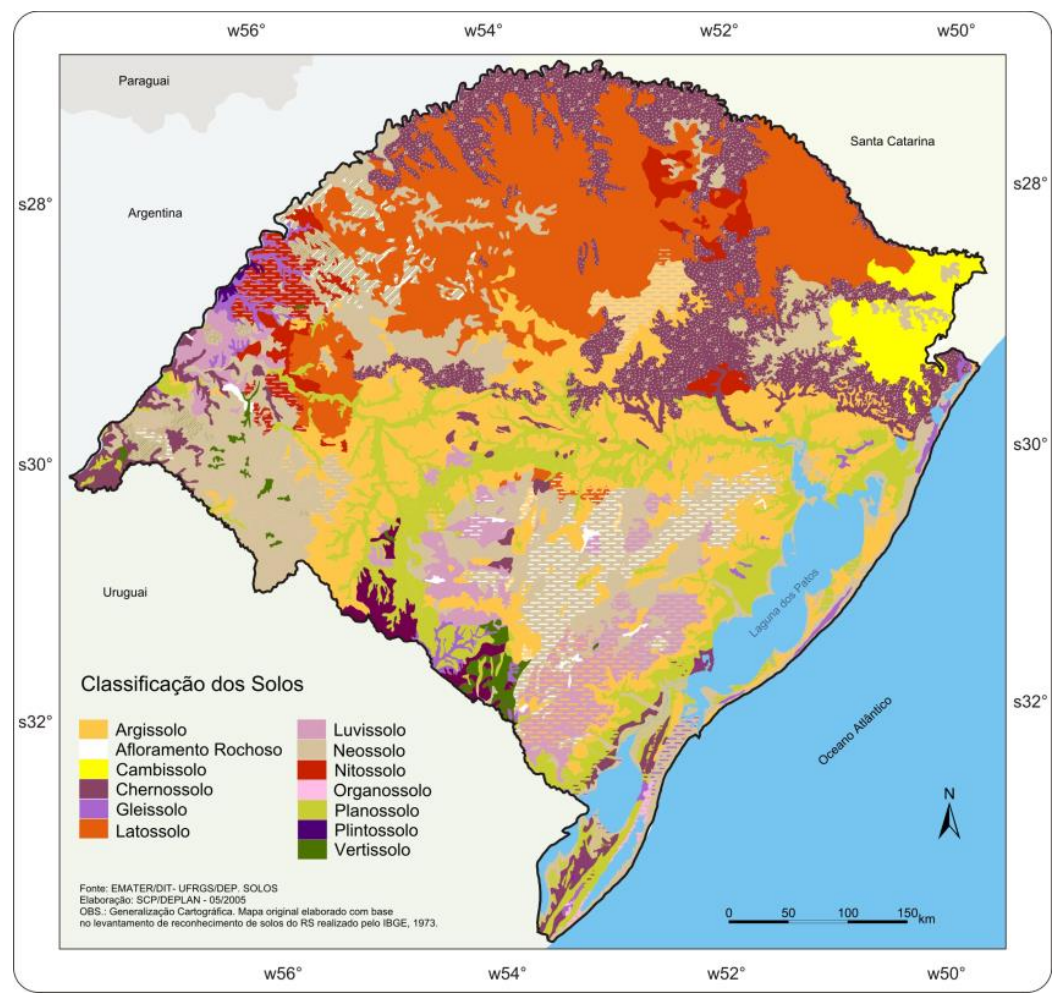

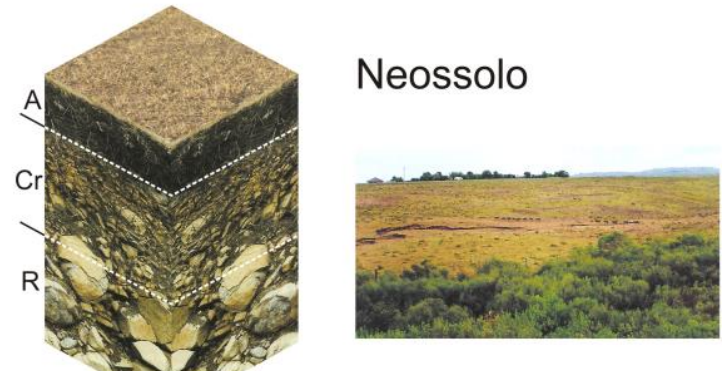

Substrato de Granito

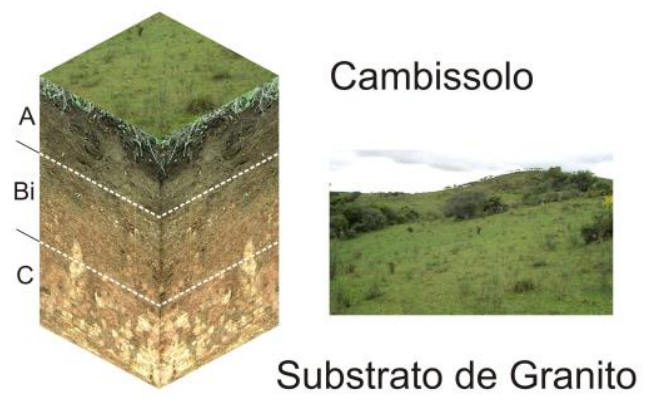

Argissolo

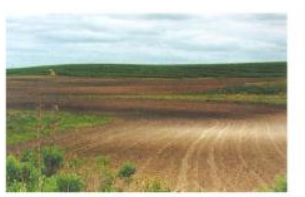

Substrato de Granito

Fonte: Adaptado de EMATER/DIT - UFRGS/DEP. SOLOS e de Streck et al. (2008). 


\section{Resultados e discussão}

No quadro 1 têm-se as médias dos totais anuais de precipitação pluvial e as médias anuais de temperatura do ar de 41 estações meteorológicas do Rio Grande do Sul. As médias dos totais anuais de precipitação pluvial, no Estado, são bem distribuídas ao longo dos doze meses do ano e varia de, aproximadamente, $1.162 \mathrm{~mm}$ (em Rio Grande, estação localizada a sudeste) a $2.162 \mathrm{~mm}$ (em São Francisco de Paula, estação localizada a nordeste). Ferreira et al., (1971) constataram apenas uma pequena diminuição na distribuição da precipitação pluvial no final da primavera e no verão. Tomandose como referência a latitude de $30^{\circ} \mathrm{S}$, na parte norte do Estado, em todos os meses do ano a precipitação pluvial é mais elevada do que na parte sul. Isto é devido a maior altitude nessa parte do Estado. Mas, tanto ao norte como ao sul da latitude de $30^{\circ} \mathrm{S}$ é nas partes de maior altitude onde ocorrem as médias mais elevadas dos totais mensais de precipitação pluvial. Assim, ao norte da latitude de $30^{\circ} S$, na região de São Francisco de Paula $(2.162 \mathrm{~mm})$, localizada na parte mais alta da Serra do Nordeste, e em Soledade $(1.986 \mathrm{~mm})$ e Palmeira das Missões $(1.919 \mathrm{~mm})$, localizadas nas partes de maiores altitudes do Planalto e Missões, ocorrem os valores totais médios anuais mais elevados de precipitação pluvial e na metade sul do Estado, a partir de $30^{\circ} \mathrm{S}$, na Serra do Sudeste, em Caçapava do Sul (1.588mm).

A temperatura, no Rio Grande do Sul, apesar de apresentar variações durante o ano, apresenta as médias anuais entre $14^{\circ} \mathrm{C}$ e $21^{\circ} \mathrm{C}$. As menores médias anuais de temperatura do ar do Estado são registradas em Bom Jesus $\left(14,4^{\circ} \mathrm{C}\right)$, localizada na Região da Serra do Nordeste e as maiores, em São Borja $\left(20,1^{\circ} \mathrm{C}\right)$, no Vale do Uruguai.

Considerando as médias dos totais anuais de precipitação pluvial e as médias dos totais anuais de temperatura do ar na variação do tipo de intemperismo, o território do Rio Grande do Sul enquadrase nas condições de intemperismo químico forte e químico moderado. 0 intemperismo químico forte predomina no Planalto Norte-rio-grandense e o químico moderado predomina no Escudo sul-riograndense, na Depressão Central e na Planície Costeira (figura 3). 
Figura 3: Distribuição geográfica do intemperismo químico forte e químico moderado nas unidades geomorfológicas do Rio Grande do Sul.

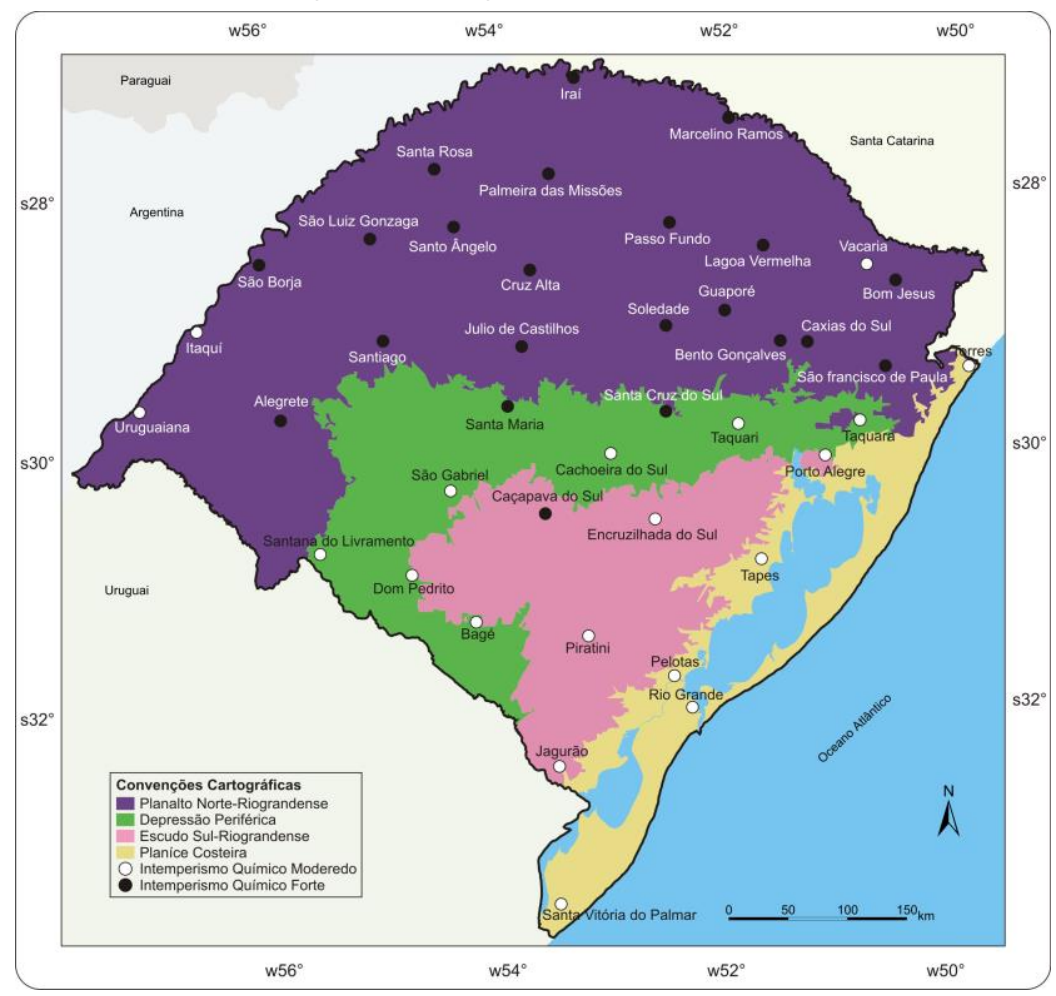

Fonte: Adaptado de HOFFMANN et al. (1997).

As disponibilidades hídricas e térmicas do Rio Grande do Sul e a variação do tipo de intemperismo favorecem a formação de solos das zonas temperadas quentes (Pedalférricos) e de zonas quentes e úmidas (Lateríticos) conforme a divisão em grupos zonais estabelecidas por Marbut (UNITED STATES DEPARMENT OF AGRICULTURE, 1935) e citada em Sthraler e Sthraler (2005) e em Press et al. (2006) (figura 4). 
Figura 4: Zoneamento dos solos zonais no Rio Grande do Sul.

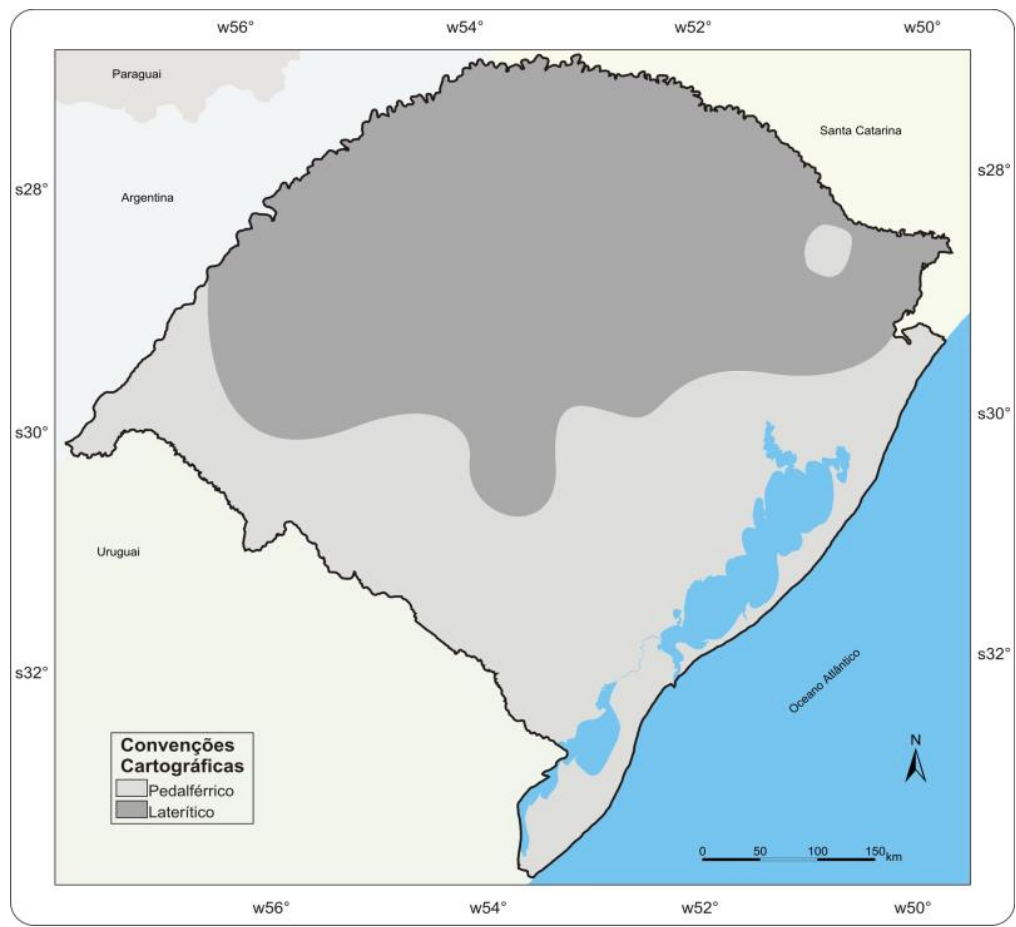

Fonte: Adaptado de STRECK et al. (2008).

Os solos do grupo Pedalférrico ocorrem, preferencialmente, em regiões de clima temperado e são descritos como solos com pronunciada lixiviação. Segundo Strhaler e Strhaler (2005), os valores médios anuais de precipitação pluvial acima de $600 \mathrm{~mm}$ são considerados condicionantes essenciais para ocorrência deste grupo. $O$ intemperismo é fundamental na desagregação e decomposição das rochas e as variações das condições decorrem da precipitação pluvial anual e da temperatura média anual. Os solos do grupo Pedalférrico formam-se em condições de intemperismo químico com índices de precipitação pluvial anual até $1.500 \mathrm{~mm}$ (TEIXEIRA et al, 2003). No Rio Grande do Sul as condições climáticas ideais para a formação desses solos são registradas nas estações meteorológicas localizadas na Depressão Central (com exceção das estações de Santa Maria e Santa Cruz do Sul), no Escudo SulRiograndense (com exceção de Caçapava do Sul), na Planície Costeira e no Planalto Norte-riograndense apenas a região de Vacaria (figura 4).

Os solos do grupo Laterítico, de climas quentes e úmidos, o intemperismo é rápido e intenso e os solos tornam-se mais profundos. Nesses ambientes, com valores abundantes de precipitação pluvial (acima de 1.500mm anuais) e temperaturas altas, o intemperismo químico, a decomposição das rochas e a vegetação de grande porte desenvolvem-se com facilidade (PRESS et al., 2006). O Rio Grande do Sul, apesar de não se localizar em latitudes de climas quentes e úmidos, apresenta condições climáticas para o intemperismo das rochas e a formação de solos Lateríticos. As condições climáticas das estações 
meteorológicas localizadas no Planalto Norte-rio-grandense enquadram-se nas possibilidades de desenvolvimento de solos zonais Lateríticos, com exceção de Vacaria, na Serra do Nordeste e de Itaquí e de Uruguaiana na região do Vale do Uruguai (figura 4).

Pelas médias dos totais anuais de precipitação pluvial e pelas médias dos totais anuais de temperatura do ar infere-se que, apesar dos meses de inverno serem considerados frios, o Rio Grande do Sul apresenta condições favoráveis ao acúmulo de água nos perfis e ao desenvolvimento de solos profundos, que podem ser formados a partir de qualquer rocha matriz. A precipitação pluvial (médias dos totais anuais e sua distribuição ao longo dos doze meses do ano) desempenha papel preponderante na formação dos solos Lateríticos.

Entretanto, o território do Rio Grande do Sul, apesar de ser abrangido por condições climáticas que determinam certa homogeneidade, se considerada as médias anuais de precipitação pluvial e temperatura do ar, apresenta, em escala regional, na maior parte do seu território, diversidade de tipos de solos. Essa evidência poderia destacar a relação com a variedade litológica do espaço geográfico do Estado. No entanto, uma mesma rocha matriz pode gerar diferentes tipos de solos. De forma contrária, rochas diferentes, quando submetidas a condições climáticas semelhantes, por um longo período de tempo, formam um mesmo tipo de solo (TEIXEIRA, et al., 2003).

Nesse sentido, foram selecionadas áreas do Estado que apresentam um mesmo substrato rochoso para diferentes tipos de solos. Na região do Planalto Norte-rio-grandense, em escala local, há áreas mapeadas como sendo de uma mesma rocha-matriz, o basalto, e que apresentam solos completamente diferentes entre si (figura 1). Esses solos, a exemplo do Neossolo, Chernossolo e Latossolo são gerados a partir de um mesmo substrato rochoso (basalto) e submetidos a condições climáticas (precipitação pluvial e temperatura) semelhantes.

As áreas compreendidas como sendo de solos do tipo Neossolo, considerados solos rasos com perfis pouco desenvolvidos ocorrem, especialmente, nas regiões da Encosta Inferior do Nordeste e no Vale do Uruguai (figura 1). Ocupam as áreas de declive com relevo fortemente ondulado. É considerado relevo forte ondulado a superfície de topografia movimentada, formada por outeiros e/ou morros (elevações de 50 a 100m e de 100 a $200 \mathrm{~m}$ de altitudes relativas, respectivamente), com declividade de 20 a 45\% (EMBRAPA, 2006). A litologia dominante é de rochas vulcânicas, remanescentes dos sucessivos derrames de lava, e sedimentos derivados das mesmas. Segundo Medeiros (1995) a maior área é de rochas básicas, porém os últimos derrames (superiores a $400 \mathrm{~m}$ ) possuem composição ácida, classificados como riolitos e riodacitos.

As áreas mapeadas como sendo de solos do tipo Chernossolo também ocorrem nas encostas do Vale do Uruguai, em relevos fortemente ondulados, nas porções mais dissecadas pelas calhas dos 
afluentes do rio Uruguai São solos rasos a profundos e sua ocorrência está associada aos Neossolos (figura 1). No contexto geológico dominam rochas vulcânicas desde básicas (maior área) até ácidas que conferem aos Chernossolos originados do basalto grau de fertilidade variado, influenciado pela percentagem de argila e quantidade de água que percola no perfil.

As áreas abrangidas pelos Latossolos são constituídas por relevos suavemente onduladas e longas extensões planas, no topo do Planalto Norte-rio-grandense. É considerado relevo suave ondulado a superfície de topografia pouco movimentada, constituída por conjunto de colinas e/ou outeiros (elevações de altitudes relativas até $50 \mathrm{~m}$ e de 50 a 100m, respectivamente), apresentando declives suaves de 3 a 8\% (EMBRAPA, 2006). Os Latossolos são solos bem drenados, com perfis profundos a muito profundos e altamente intemperizados (figura 1).

As disponibilidades climáticas das estações meteorológicas (evapotranspiração potencial e precipitação pluvial) de Santo Ângelo (figura 5) e de Irai (figura 6) indicam condições de zonas de clima Úmido, Super-úmido e Híper-úmido.

Figura 5: Climograma relacionando evapotranspiração potencial e precipitação pluvial, médias dos totais anuais da estação meteorológica de Santo Ângelo

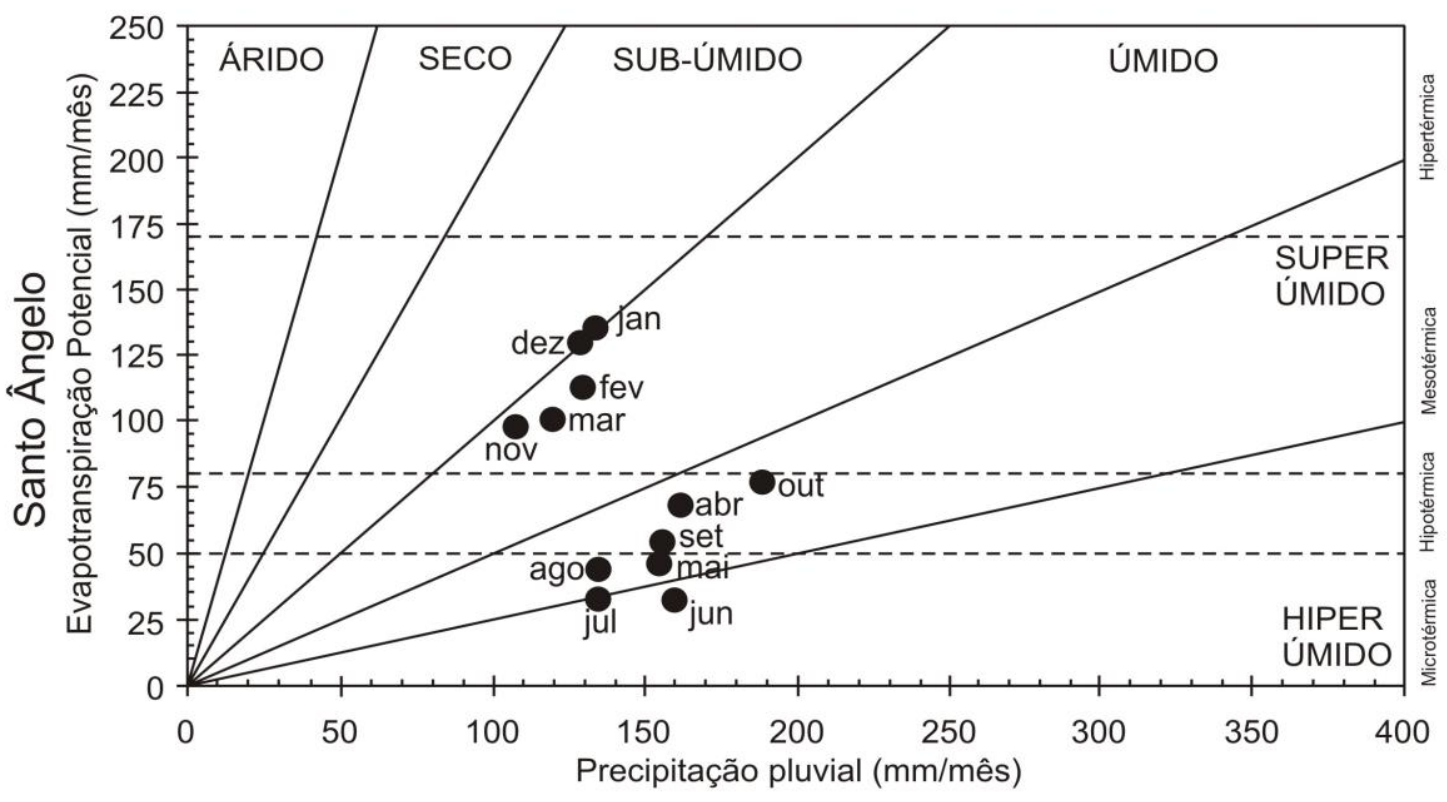

Fonte: Adaptado de Camargo (1960). 
Figura 6: Climograma relacionando evapotranspiração potencial e precipitação pluvial, médias dos totais anuais da estação meteorológica de Iraí

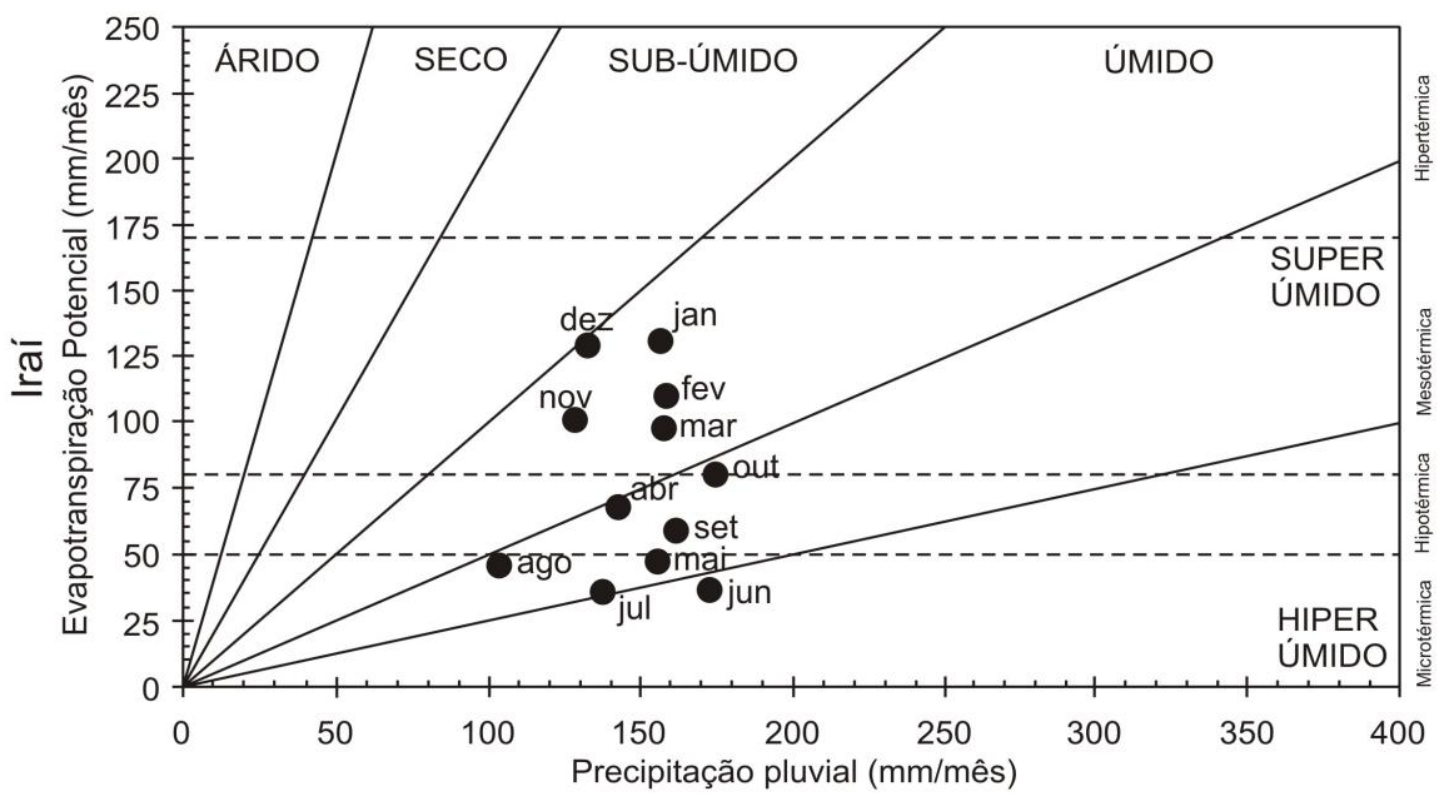

Fonte: Adaptado de Camargo (1960).

No contexto geológico onde dominam derrames vulcânicos básicos (basalto) em relevos de coxilhas suave ondulado, submetidos a clima úmido (precipitação pluvial bem distribuída ao longo do ano) os Latossolos são mais argilosos e com presença abundante de limalha de ferro (magnetita de coloração preta) nos valos de drenagem.

As condições climáticas (precipitação pluvial e temperatura) da metade norte do Estado do Rio Grande do Sul e o substrato rochoso de basalto (predominante nessa região) favorecem a formação de solos zonais do grupo Laterítico, profundos e altamente intemperizados. As exceções ocorrentes estão associadas às regiões de maior declive do relevo, onde o escoamento superficial da água é maior e mais rápido e a infiltração é menor e isso, provavelmente, desfavorece a ação do intemperismo químico desencadeado, especialmente, pela disponibilidade de água no perfil.

$\mathrm{Na}$ metade sul do Estado, especialmente, na região do Escudo Sul-rio-grandense têm-se diversidade geológica e de formação bastante antiga (Era Paleozoica), com ocorrência de solos distintos entre si. As condições climáticas, se consideradas as médias dos totais anuais de precipitação pluvial e as médias de temperatura do ar, apresentam certa homogeneidade no período avaliado.

Segundo o Departamento Nacional da Produção Mineral (1984b) há ocorrência expressiva de granitos em áreas como São Sepé, Caçapava do Sul, Lavras do Sul, Dom Feliciano, Encruzilhada do Sul. No contexto geológico de rochas graníticas têm-se solos diferentes entre si e submetidos a condições climáticas (precipitação pluvial e temperatura) semelhante, a exemplo do Neossolo, 
Cambissolo e Argissolo. Estes solos abrangem uma área considerável do Escudo Sul-rio-grandense (figura 2) e ocorrem, especialmente, no relevo ondulado a forte ondulado da Serra do Sudeste. Os Neossolos originados a partir do granito ocorrente no Escudo Sul-rio-grandense, de litologia muito antiga, são solos de formação muito recente e apresentam perfis rasos e pouco profundos e, geralmente, estão associados à afloramentos de rochas.

As áreas de solos do tipo Cambissolo originados do granito, também ocorrem na Serra de Sudeste em relevos fortemente ondulados (figura 2). São solos rasos a profundos e sua ocorrência está associada à acumulação de matéria orgânica. É comum a presença de fragmento de rocha no perfil do Cambissolo, atestando pouca intemperização do material de origem. Segundo Streck et al. (2008) a presença de material orgânico no topo do perfil está associada às condições climáticas (menores temperaturas e ocorrência de geadas). No Rio Grande do Sul a ocorrência dos Cambissolos corresponde às regiões de maior altitude (Campos de Cima da Serra, Encosta Superior do Nordeste em que predominam rochas básicas do tipo riolito e Serra do Sudeste em que predominam granitos). Nessas regiões de maior altitude, as temperaturas mais baixas favorecem a acumulação da matéria orgânica e a maior precipitação pluvial condiciona o intemperismo.

Segundo Streck et al. (2008) os Cambissolos são solos em processo de transformação e por isso ainda apresentam poucas características para serem enquadrados em outras classes de solos mais desenvolvidas. Na região ao sul da Encosta do Sudeste e Serra do Sudeste, no entorno de Piratini, os Cambissolos já ocorrem associados aos Luvissolos e aos Argissolos também originados do granito.

As áreas abrangidas pelos Argissolos são constituídas por relevos desde suave ondulado até forte ondulado. Ocorrem em longas extensões planas da Depressão Central e, de forma esparsa em todo o território do Rio Grande do Sul, a partir de diferentes tipos de rochas. Na Serra do Sudeste têmse Argissolos formados do granito (figura 2). Os Argissolos são solos geralmente profundos a muito profundos.

As disponibilidades climáticas (evapotranspiração potencial e precipitação pluvial) das estações meteorológicas de Encruzilhada do Sul (figura 7) e de Piratini (figura 8) indicam condições de zonas de clima Úmido, Super-úmido e Híper-úmido. 
Figura 7: Climograma relacionando evapotranspiração potencial e precipitação pluvial, médias dos totais anuais da estação meteorológica de Encruzilhada do Sul

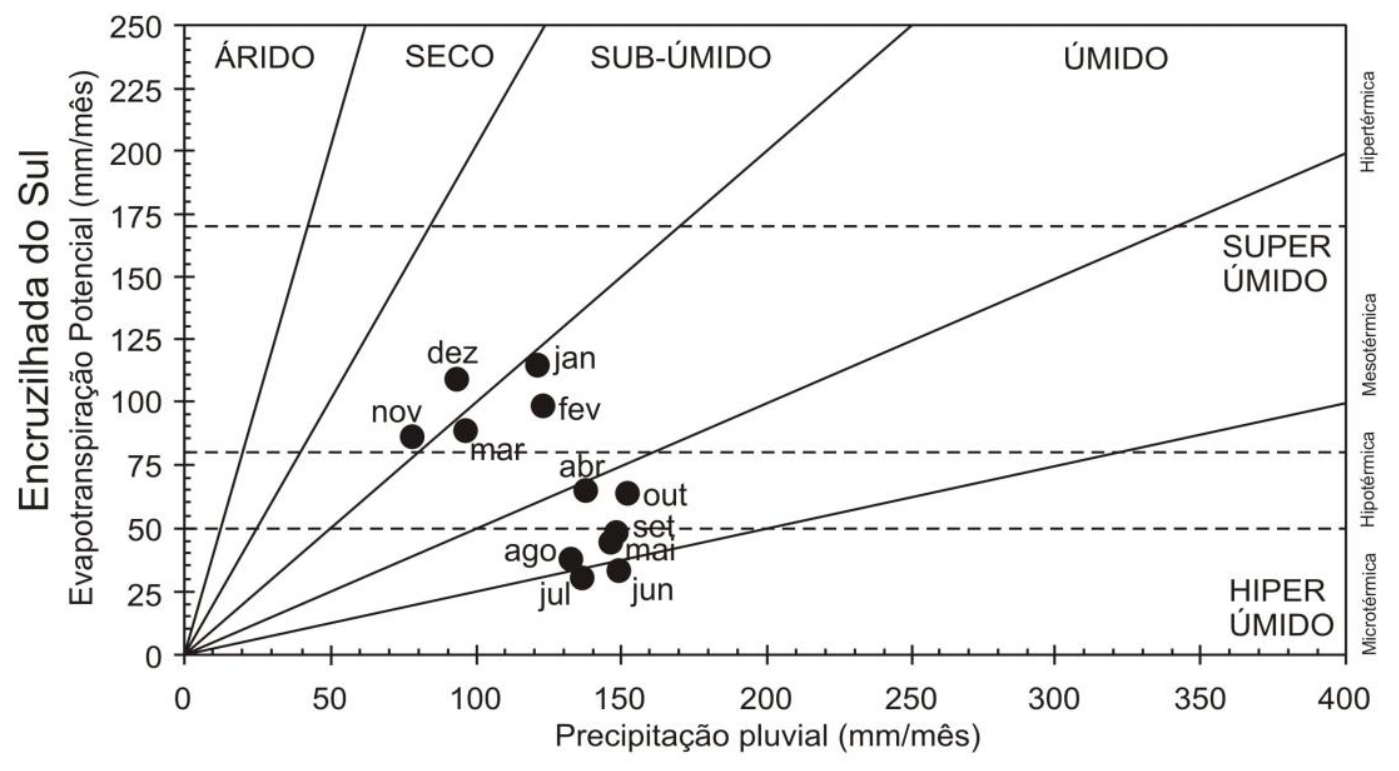

Fonte: Adaptado de Camargo (1960).

Figura 8: Climograma relacionando evapotranspiração potencial e precipitação pluvial, médias dos totais anuais da estação meteorológica de Piratini

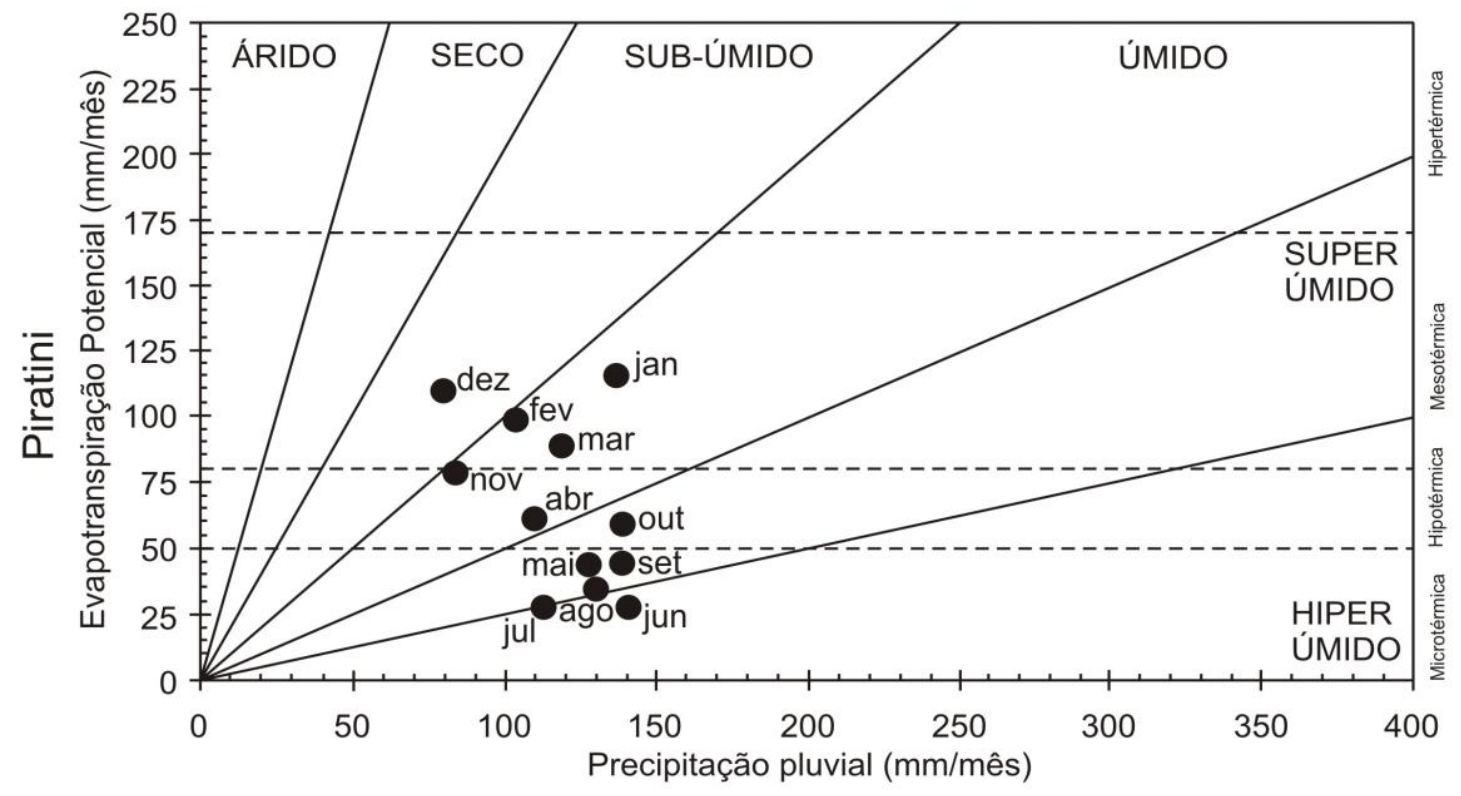

Fonte: Adaptado de Camargo (1960).

Pelos resultados obtidos nos climogramas (evapotranspiração e precipitação pluvial), nas estações meteorológicas utilizadas teve-se condições de clima Úmido, Super-úmido e Híper-úmido.

Nas áreas com ocorrência de substrato rochoso de basalto e com condições climáticas semelhantes (evapotranspiração e precipitação pluvial) têm-se diferentes tipos de solos (Neossolo, Chernossolo e 
Latossolo). Da mesma forma, nas áreas com ocorrência de substrato rochoso de granito e com condições climáticas semelhantes (evapotranspiração e precipitação pluvial) têm-se tipos de solos distintos (Neossolo, Cambissolo e Argissolo).

\section{Conclusões}

Os solos zonais do Rio Grande do Sul compreendem solos Lateríticos e solos Pedalférricos.

Os Lateríticos, considerados solos de climas muito úmidos e quentes, são condicionados pelo intenso intemperismo químico. Nesses ambientes, a facilidade da decomposição das rochas favorece a formação de perfis mais profundos.

O Rio Grande do Sul, apesar de não se localizar em latitudes de climas quentes e úmidos, apresenta as condições climáticas que favorece 0 intemperismo das rochas. Essas condições climáticas foram constatadas nos dados das estações meteorológicas localizadas no Planalto Norte-rio-grandense, com exceção de Vacaria, na Serra do Nordeste e de Itaquí e de Uruguaiana na região do Vale do Uruguai.

Portanto, as condições climáticas que abrangem a metade norte do Estado com médias anuais de precipitação pluvial acima de $1.500 \mathrm{~mm}$, favorecem o desenvolvimento dos solos Lateríticos que, nessa região do Estado, são representados predominantemente pelos Latossolos.

Os Pedalférricos ocorrem, preferencialmente, em regiões de clima temperado e são descritos como solos com pronunciada lixiviação, que ocorrem em condições de intemperismo químico com índices de precipitação anual acima de $600 \mathrm{~mm}$. No Rio Grande do Sul as condições climáticas ideais para a formação desses solos são registradas nas estações meteorológicas localizadas na Depressão Central (com exceção das estações de Santa Maria e Santa Cruz do Sul), no Escudo Sul-rio-grandense (com exceção de Caçapava do Sul), na Planície Costeira e no Planalto Norte-rio-grandense apenas a região de Vacaria. No Estado, os solos Pedalférricos, são representados, predominantemente pelos Neossolos e Cambissolos.

\section{Referências}

AZEVEDO, A. C.; DALMOLIN, R. S. D. Solos e ambiente: uma introdução. Santa Maria: Pallotti, 2006. $100 \mathrm{p}$.

BIGARELLA, J. J. Estrutura e origem das paisagens tropicais e subtropicais. Vol. 1. Florianópolis: Editora da UFSC, 1994. 424 p.

CAMARGO, A. P. Viabilidade e limitações climáticas para a cultura do milho no Brasil. In: Instituto Brasileiro de Potassa. Cultura e Adubação do Milho. São Paulo. 1960. 541 p.

DEPARTAMENTO NACIONAL DA PRODUÇÃO MINERAL (DNPM). Geologia do Brasil. Brasília. 1984(b). 840 p.

EMBRAPA. Sistema Brasileiro de Classificação de solos. Rio de Janeiro: Embrapa solo, 2006, 306 p. FERREIRA, M., ESTEFANEL, V.; BURIOL, G. A. Estimativa das temperaturas médias mensais e anuais do Estado do Rio Grande do Sul. Rev. Centro Ciências Rurais, Santa Maria, v. 1, nº 4, p. 21-52, 1971. 
HOFFMANN, G. R. et al. Rio Grande do Sul. Aspectos da Geografia. Porto Alegre: Martins Livreiro, 1997. $104 \mathrm{p}$.

INSTITUTO DE PESQUISAS AGRONÔMICAS. Atlas agroclimático do estado do Rio Grande do Sul. Porto Alegre: Secretaria da Agricultura e Abastecimento, 1989, $102 \mathrm{p}$.

JENNY, H. Factors of soil formation. New York: McGraw-Hill. 1941. $281 \mathrm{p}$.

MARBUT, C. F. Soils of the United States: Atlas of American Agriculture, Part III, U. S. Government Printing Office, Washington, D. C., 1935. 630 p.

MEDEIROS, E. R. at. al. Degradação ambiental da região centro-oeste do Rio Grande do Sul. Ciência \& Ambiente. Santa Maria, Rs. Volume 11. p. 53-64, 1995.

PRESS, F.; SIEVER, R.; GROTZINGER, J.; JORDAN, T. H. Para entender a Terra. São Paulo: Bookman. 2006. $655 \mathrm{p}$.

STRECK, E. V. et al. Solos do Rio Grande do Sul. Porto Alegre: UFRGS, 2002. 107 p.

STRECK, E. V. et al. Solos do Rio Grande do Sul. Porto Alegre: UFRGS, 2008. 222 p.

STRAHLER, A. N.; STRAHLER, A. N. Geografia Física. Barcelona, 2005. 550 p.

SUGUIO, K. Geologia sedimentar. São Paulo: Edgard Blücher Ltda, 2003. 400 p.

TEIXEIRA, W.; TOLEDO, M. C. M.; FAIRCHILD, T. R.; TAIOLI, F. Decifrando a Terra. São Paulo: Oficina de textos. 2003. $558 \mathrm{p}$.

THORNTHWAITE, C. W. The climates of North according to a new classification. The Geographical Review, Oct., p. 633-655, 1931.

VIEIRA, L. S. Manual da ciência do solo. São Paulo: Ed. Agronômica Ceres, 1975. 464 p.

(Recebido em 06-01-2016; Aceito em 20-02-2017) 